\title{
Vaccination Adverse Outcomes and Costs of Vaccine Injury Claims (VICs): Past, Present and Covid-19
}

\author{
John Paull \\ University of Tasmania, Hobart, Tasmania, Australia.
}

How to cite this paper: John Paull. (2021) Vaccination Adverse Outcomes and Costs of Vaccine Injury Claims (VICs): Past, Present and Covid-19. International Journal of Clinical and Experimental Medicine Research, 5(1), 1-5. DOI: 10.26855/ijcemr.2021.01.001

Received: October 30, 2020 Accepted: November 28, 2020 Published: December 11, 2020

*Corresponding author: John Paull, University of Tasmania, Hobart, Tasmania, Australia.

Email: j.paull@utas.edu.au

\begin{abstract}
The US National Vaccine Injury Compensation Program (VICP) has paid out US\$4,431,468,456 for 7,575 vaccine injuries from (financial years) 1989 through 2020. The average settled claim was US\$585,012 per claimant. Of the total claims filed $(n=22,372), 94 \%$ were claims for non-fatal injury $(n=21,035)$ and $6 \%$ were claims for death $(n=1,337)$. Of the total claims filed, $34 \%$ were successful $(n=7,611), 52 \%$ were dismissed $(n=11,671)$, and $14 \%$ were not progressed $(n=3,090)$. The VICP acts as an indemnity shield for the vaccine industry. The VICP offers a non-litigious path to compensation for the vax-injured. The VICP is funded by a vax tax of US 75 cents per disease per dose. Injury claims can be rejected because the claim is filed out of time, the particular vaccine is not a VICP-listed vaccine, the injury is not a VICP-listed injury (e.g. autism is not listed), or the injury is not sufficiently severe. There were 1.39 compensated injuries per one million distributed vaccine doses ( $n=5,233$ compensated injuries for 3,761,744,351 distributed vaccine doses; 2006 through 2018). The VICP payout rate is US $\$ 813$ million for vax injuries per one billion vax doses. Based on past experience of vaccination injury, mass vaccination of billions of people for Covid-19 can be anticipated to produce vaccine injuries (including deaths). Based on the historical data of the VICP across 30 different vaccines, vaccinating a billion people with Covid-19 vaccines, can be anticipated to manifest a scenario of US\$813 million of vaccine injuries (as an underestimate). Vaccinating the world's population ( $\mathrm{n}=7.8$ billion) with an initial Covid-19 vaccine dose may generate US\$6.3 billion of vaccine injuries. A two dose Covid-19 vaccine (prime-boost regimen) may generate US $\$ 12.7$ billion of vaccine injuries. A Covid-19 vax regime of (say) three booster shots may generate US $\$ 25.4$ billion of vaccine injuries. These scenario extrapolations assume that the Covid-19 vaccines (although developed and administered under pandemic duress), are neither more nor less injurious than the vaccines $(n=30)$ of VICP experience, which have been tested, certified, manufactured, stored and administered to US standards, and that there is no differential between the compensable value of US and non-US injuries.
\end{abstract}

\section{Keywords}

National Vaccine Injury Compensation Program (VICP), Vaccine injury claims (VICs), immunisation, vax injury, vax tax, Covid-19, SARS-CoV-2, Corona virus, pandemic 


\section{Introduction}

A maxim states that "there is no such thing as a free lunch" [1]. In science, business and life, where there are benefits to be reaped, there are prices to be paid. Vaccinations are not exempt from the sentiments of the maxim. This pits vax-proponents (who argue the benefits), against vax-antagonists (who argue the costs).

The general expectation is that a vaccine is "safe and effective" [2]. The White House Coronavirus Task Force spokesperson, Dr Anthony Fauci, has recently reformulated this expectation as "safe enough and effective enough" [3]. This dilution of expectations reflects the real or perceived urgency for a vaccine to deal with the Covid-19 pandemic, and the resulting foreshortened timeline for the chain of development, testing and approval of new vaccines. Vaccine development is a process that typically can take decades [4]. "Operation Warp Speed" is a US partnership of the Department of Health and Human Services (DHHS) and the Department of Defense (DoD) to fast-track Covid-19 vaccines [5].

With the prevailing Covid-19 pandemic, much hope has been vested in vaccines, although there is some scepticism [6]. There are many prospective Covid-19 vaccines at various stages of development. One report states that there are 88 pre-clinical vaccines, 49 in clinical trials, 35 in Phase 1 trials, 14 in Phase 2 trials, 11 vaccines in Phase 3 trials, 6 vaccines approved for limited use, and none approved for "full use" [7].

Vaccination is a multi-billion dollar industry. The World Health Organization estimates the global demand for vaccines at 3.5 billion doses per annum with a market value of US\$26 billion [8]. Global vaccine revenues are projected to be US\$54.2 billion in 2020 [9]. The US VICP is funded by an excise levy of US 75 cents per disease per dose (a single disease vax will attract a 75 cents levy per dose; a multi-disease vax will attract multiple 75 cent levies per dose, so that an MMR vaccination-measles, mumps and rubella—will attract a US\$2.25 levy).

The US has a no-fault vaccine injury compensation (VIC) scheme and a further 24 countries have similar such schemes [10]. This means that most countries (87\%) have no VIC scheme. In the absence of a VIC scheme, to achieve compensation for vaccine injuries the harmed party would have to proceed through tort claims, which will be expensive and time consuming and quite likely beyond the capacity of most injured parties (including vaccine injured children and the deceased).

The US Department of Justice states that: “The National Childhood Vaccine Injury Act of 1986 ... created a unique mechanism for compensating persons injured by vaccinations. The National Vaccine Injury Compensation Program (the 'VICP' or the 'Program') (42 U.S.C. §§ 300aa-10 et seq.) is an alternative to traditional products liability and medical malpractice litigation for persons injured by their receipt of one or more of the standard childhood vaccines" [11].

The US experience is that is that VICP has facilitated the avoidance of expensive litigation: "The VICP is designed to encourage vaccination by providing a streamlined system for compensation in rare instances where an injury results from vaccination. Over the past 30 years, the VICP has succeeded in providing a less adversarial, less expensive, and less time-consuming system of recovery than the traditional tort system that governs medical malpractice, personal injury, and product liability cases” [11].

The VICP has benefited the vaccination industry: "A significant, positive result of the Program is that costly litigation against drug manufacturers and health care professionals who administer vaccines has virtually ceased. Although an individual who is dissatisfied with the Court's final judgment has the option to file a lawsuit in State or Federal court, very few lawsuits have been filed since the Program began. The supply of vaccines in the U.S. has stabilized, and the development of new vaccines has markedly increased” [11].

The VICP has operated in the US for three decades. The fate of vaccine injury claims is examined in the present paper and some lessons, projections and scenarios for vaccine injuries from prospective Covid-19 vaccines are presented.

\section{Material and methods}

The vaccine injury data for USA reported in the present paper are sourced from the US Health Resources \& Services Administration [12]. The data of the National Vaccine Injury Compensation Program (VICP) date from 1989 through to the present. World population and countries data are reported from the Worldometer tallies [13, 14]. Scenarios of potential Covid-19 vaccines are based on a single dose and also on current expectations that multiple doses will be required to confer or maintain Covid-19 immunity [15].

\section{Results and discussion}

The total payout over the three decades of the US VICP is US\$4,431,468,456 (of which 9.8\% was for the legal 
fees of claimants). Total payouts per annum for the past eight years under VICP have fluctuated within the range of US\$200 million to US\$300 million per annum (Figure 1). The highest total annual payout was $\$ 282,099,306$ (in 2017). It appears that the vax injury expenditure of the VICP is funded within the vax tax revenue stream (of the excise levy of US 75 cents per disease per vax dose).

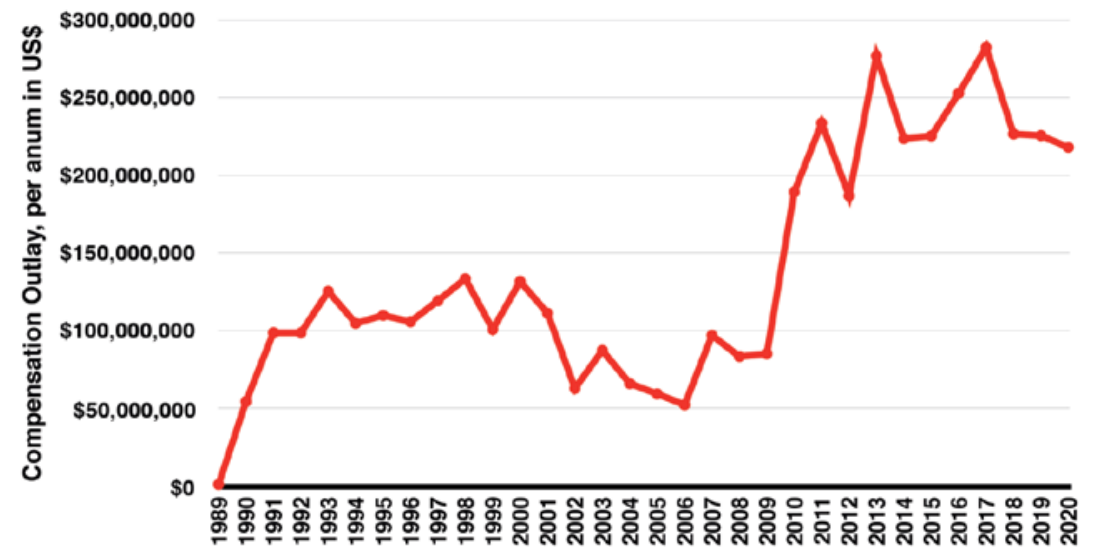

Figure 1. Vaccination injury compensation paid under the US VICP (1989-2020) [Data source: 12].

Of the total vax injury claims filed $(n=22,372), 94 \%$ were claims for non-fatal injury $(n=21,035)$ and $6 \%$ were claims for death $(n=1,337)$ [12]. Of the total vax injury claims filed $(n=22,372), 34 \%$ were successful $(n=7,611)$, $52 \%$ were dismissed $(n=11,671)$, and $14 \%$ did not progress to adjudication $(n=3,090)$ (Figure 2).

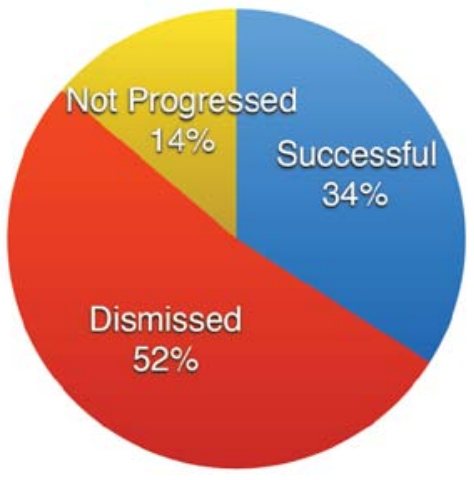

Figure 2. The fate of vaccine injury claims under the US VICP (1989-2020) [Data source: 12].

Vax injury claims average 678 per year, although there have been substantial fluctuations with peaks in 1991 $(\mathrm{n}=2,718)$ and $2003(\mathrm{n}=2,592)$ (Figure 3).

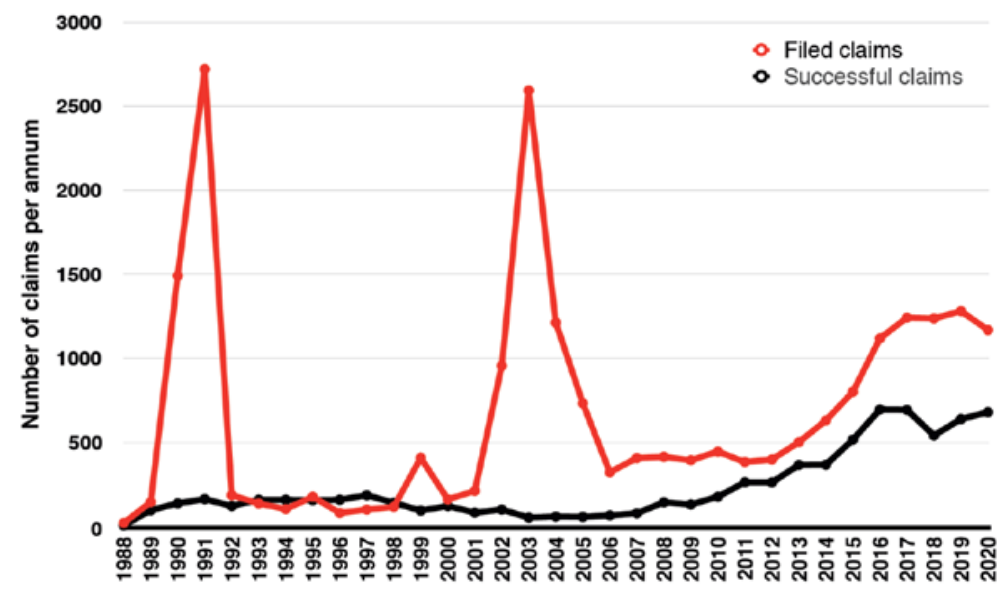

Figure 3. Vaccination injury claims filed and claims compensable (i.e. successful) under the US VICP (1989-2020) [Data source: 12]. 
The total number of successful (“compensable”) vaccine injury claims over the 33 years of the VICP is 7,611. Of the claims that proceed to adjudication $(n=19,282), 39 \%$ are successful $(n=7,611)$ while $61 \%$ are unsuccessful $(n=11,671)$. Successful claims average 231 per year, with a peak of 698 in 2016. The peaks of vaccine injury claims are not reflected in the corresponding compensable claims (Figure 3). Claims may not proceed to adjudication because they are filed out of time, the harming vaccine is not a listed vaccine, the injury is not a listed injury (e.g. autism is not listed) [16], the injury is not sufficiently severe, or the claim is withdrawn by the claimant [12].

The claim peaks (of 1991 and 2003) (Figure 3) suggest that there is considerable elasticity in the number of vaccine injury claims, and that there is a pool of cryptic vaccine injuries that remain silent (and not submitted for compensation). Filed claims take several years to progress to adjudication [12] and this accounts for that, in some years, the successful claims exceeded the filed claims (Figure 3).

There were 1.39 compensated vax injuries per one million distributed vax doses $(n=5,233$ compensated injuries, for 30 listed vaccines, totalling 3,761,744,351 distributed vax doses; 2006 through 2018) [12].

\subsection{Covid-19 Scenarios}

A global Covid-19 vaccination programme would be the world's biggest, boldest, and most ambitious vaccination programme ever embarked upon. Based on the past experience of vaccination injury, mass vaccination of billions of people for Covid-19 can be anticipated to produce vaccine injuries (including deaths). Mass vaccinations precipitate unintended adverse outcomes for some [12]. A Hippocratic dictum of "first, do no harm" cannot be realised in a mass vax rollout, and must be substituted with a cost/benefit analysis.

Like all trade-offs, there is point of inflexion where the costs exceed the benefits, and beyond which retreat is the better course. For example, if the cost per measles case is US\$307 and the adverse-event cost of measles vaccination per vaccinated subject is US\$1.93 (UK data), then a measles incidence of 1 in 159 of the population is the cost/benefit break-even point [17]. Vaccinating where the incidence is less than the break-even point is contraindicated on such a monetary analysis, and the cost of vax injuries will exceed the benefits of vaccination.

Historical vaccine injuries amount to US\$813 million of vax injuries per one billion of vax doses (based on the US VICP experience of 1.39 vaccine injuries per million vaccine doses and the average compensation payout of US\$585,012). The figure of US\$813 million of vax injuries per one billion vax doses is a lower-bound estimate of vax injury [the figure would be higher if historical vax injury payouts were adjusted upwards to net present value (NPV)].

The VICP experience suggests the scenario that Covid-19 vaccines can be expected to cause vax injuries at the rate of $>$ US $\$ 813$ million of vax injuries per one billion vax doses. Vaccinating the world's population ( $\mathrm{n}=7.8$ billion) as has been proposed [18] with an initial Covid-19 vaccine dose may generate $>$ US\$6.3 billion of vax injuries. A two dose Covid-19 vaccine (prime-boost regimen) may generate US\$12.7 billion of vax injuries. A Covid-19 vax regime of (say) prime plus three booster shots may generate > US $\$ 25.4$ billion of vax injuries.

These scenarios assume that the Covid-19 vaccines are neither more nor less injurious than the vaccines $(n=30)$ of the VICP experience (which have been tested, certified, manufactured, stored and administered to US standards), and that there is no differential between the compensable value of US and non-US injuries. This may be an optimistic assumption for vaccines developed at 'warp speed' under pandemic duress, certified under a foreshortened timeline, manufactured at unprecedented scale and speed, and administered in haste and under widely variant conditions, including Third World conditions.

\section{Conclusions}

Mass vaccination of much of the world's population presents a perhaps once-in-a-century bonanza opportunity for the vaccination industry. A global mass vaccination programme, as envisaged with Covid-19 vaccines, exposes populations to the risk of individual harms for the proposed benefit of the many (and the vaccination industry). The indemnity shield of a vaccine injury scheme facilitates profits being privatised and costs being socialised. Care needs to be taken that societal benefits accruing from a Covid-19 vaccine are not at the cost of individualised harms.

It is claimed that: "The United States has the safest, most effective vaccine supply in history. In the majority of cases vaccines cause no side effects, however they can occur, as with any medication—but most are mild” [12, p. 1]. Vaccine schemes managed elsewhere may generate a higher level of vaccine injury.

Of the world's countries $(n=195), 87 \%(n=170)$ do not have a vax injury compensation program [10, 14]. This leaves the populations of most countries vulnerable to vaccine injury with little prospect of compensation. This lack needs to be remedied before a mass roll out of Covid-19 vaccines. The absent VICPs could be implemented 
on a country-by-country basis. However, given that Covid-19 is a global pandemic, with no country spared the risks, a global VICP could be implemented (by, for example, an agency of the United Nations, perhaps the WHO).

A vax tax of US\$1 per Covid-19 vaccine dose could fund such VICPs. A modest increase (of 33\%) over the existing US excise levy of US 75 cents would acknowledge that fast-tracked vaccines, that are fast-track manufactured, and fast-track delivered globally, without, at least in some cases, the benefit of first-world standards, may carry some greater risk of harm for recipients and populations.

There is already a global smorgasbord of Covid-fatigue, lockdown-fatigue, vaccine hesitation, vaccination resistance, vaccine scepticism, vaccine conscientious objection, and entrenched anti-vax sentiment. In an era of increasing distrust of authority [19], and in a world where governance transparency is often denied to citizens, a programme of mass vaccination needs to proceed with great caution, with transparency, and with tolerance and engagement with those on the spectrum of what the WHO calls "vaccine hesitancy" [20].

\section{References}

[1] Friedman, M. (1975). There’s No Such Thing as a Free Lunch. Chicago, IL: Open Court Publishing Company.

[2] Slaoui, M. and M. Hepburn. (2020). Developing Safe and Effective Covid Vaccines-Operation Warp Speed's Strategy and Approach. The New England Journal of Medicine, 2020, 383(29 October): 1701-1703.

[3] CNN, The Situation Room: U.S. Death Toll Tops 192,000 with over 6.4 Million Cases; One- on-One with Dr. Anthony Fauci; Rep. Nancy Pelosi (D-CA) Is Interviewed About The 9/11 Attacks, Disunity Amid Coronavirus Pandemic; Prosecutor In Durham Investigation Of Russia Probe Origins Resigns, Reportedly Due In Part To Pressure To Wrap Up Before Election. Aired 5-6p ET. 2020, 11 September. Atlanta, GA: CNN Transcripts.

[4] Colorossi, N. (2020). How long it took to develop 12 other vaccines in history. Business Insider Australia, 2020. July 18.

[5] CDC, Coronavirus Disease 2019 (COVID-19): Frequently Asked Questions about COVID-19 Vaccination. 2020, 14 October. Atlanta, GA: Centers for Disease Control and Prevention (CDC).

[6] Hart, E. M. (2020). Rapid response to: Covid-19: Less haste, more safety. British Medical Journal, 2020. 1 September. 379(m3258).

[7] Corum, J., S.-L. Wee, and C. Zimmer. (2020). Coronavirus Vaccine Tracker. The New York Times, 2020. 28 October.

[8] WHO, Global Vaccine Market Report. (2019, December). Geneva: World Health Organization (WHO).

[9] Mikulic, M. (2019). Global Vaccine Market Revenues 2014-2020. 2019, Hamburg, DE: Statista.

[10] Wood, N. (2020). Australia needs a vaccine injury compensation scheme: Upcoming COVID-19 vaccines make its introduction urgent. Australian Journal of General Practice, 2020, 49(Suppl. 36): 1-2.

[11] DoJ, Vaccine Injury Compensation Program. (2018). Washington, DC: United States Department of Justice (DoJ).

[12] HRSA, Data \& Statistics. 2020, 1 October 2020 update. Rockville, MD: Health Resources \& Services Administration (HRSA).

[13] Worldometer, Current World Population: 7,821,697,000. 2020, worldometers.info (accessed 29 Oct 2020).

[14] Worldometer, Countries in the World: 195. 2020, worldometers.info (accessed 29 Oct 2020).

[15] McNamara, A. Multiple vaccine doses could be necessary to protect from coronavirus, Bill Gates says. McNamara, Audrey, 23 July. New York, NY: CBS News.

[16] HRSA, Vaccine Injury Table. (2017). Rockville, MD: Health Resources \& Services Administration (HRSA).

[17] Carabin, H., et al. (2002). The average cost of measles cases and adverse events following vaccination in industrialised countries. BMC Public Health, 2002, 2(22): 1-13.

[18] Khamsi, R. (2020). If a coronavirus vaccine arrives, can the world make enough? Researchers warn production constraints and hoarding could limit SARS-CoV-2 vaccine supplies. Nature, 2020, 580: 578-580.

[19] Paull, J. (2020). Science Versus Public Sentiment: “Covid-19 is not a Bioweapon Created in a Laboratory, Say UK Scientists”, “Nope, Don’t Believe It”, Say UK Public. International Journal of Clinical and Experimental Medicine Research, 2020, 4(3): 93-100.

[20] WHO. (2020). Improving vaccination demand and addressing hesitancy. Geneva: World Health Organization. 